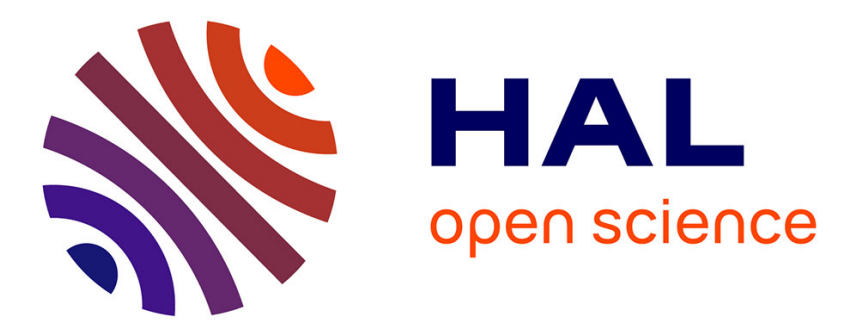

\title{
Dual-color control and inhibition of direct laser writing in silver-containing phosphate glasses
}

Yannick Petit, Konstantin Mishchik, Nadezda Varkentina, Nicolas

Marquestaut, Arnaud Royon, Inka Manek-Hönninger, Thierry Cardinal, Lionel Canioni

\section{To cite this version:}

Yannick Petit, Konstantin Mishchik, Nadezda Varkentina, Nicolas Marquestaut, Arnaud Royon, et al.. Dual-color control and inhibition of direct laser writing in silver-containing phosphate glasses. Optics Letters, 2015, 40 (17), pp.4134-4137. 10.1364/OL.40.004134 . hal-01193278

\section{HAL Id: hal-01193278 \\ https://hal.science/hal-01193278}

Submitted on 10 Mar 2021

HAL is a multi-disciplinary open access archive for the deposit and dissemination of scientific research documents, whether they are published or not. The documents may come from teaching and research institutions in France or abroad, or from public or private research centers.
L'archive ouverte pluridisciplinaire HAL, est destinée au dépôt et à la diffusion de documents scientifiques de niveau recherche, publiés ou non, émanant des établissements d'enseignement et de recherche français ou étrangers, des laboratoires publics ou privés. 


\title{
Dual-color control and inhibition of direct laser writing in silver-containing phosphate glasses
}

\author{
Yannick Petit, ${ }^{1,2, *}$ Konstantin Mishchik, ${ }^{2}$ Nadezda Varkentina, ${ }^{2}$ Nicolas Marquestaut, ${ }^{2}$ \\ Arnaud Royon, ${ }^{2}$ Inka Manek-Hönninger, ${ }^{2}$ Thierry Cardinal, ${ }^{1}$ and Lionel Canioni ${ }^{2}$ \\ ${ }^{1}$ Univ. Bordeaux, CNRS, ICMCB, UPR 9048 CNRS, F-33608 Pessac, France \\ ${ }^{2}$ University of Bordeaux, CNRS, CEA, CELIA, UMR 5107, 351 Cours de la Liberation, 33405 Talence Cedex, France \\ *Corresponding author: yannick.petit@u-bordeaux.fr
}

Received Month X, XXXX; revised Month X, XXXX; accepted Month X,

XXXX; posted Month X, XXXX (Doc. ID XXXXX); published Month X, XXXX

We report on dual-color control of femtosecond direct laser writing (DLW) in a non commercial silver-containing zinc phosphate glass, thanks to an additional illumination with a $\mathrm{cw}$ (continuous wave) UV laser either after the femtosecond irradiation or simultaneously. By tuning the $\mathrm{cw}$ UV power, we demonstrate the tunable control and inhibition of the production efficiency of laser-induced fluorescent silver clusters, leading up to $100 \%$ inhibition for simultaneous coillumination when the laser writing is performed close enough to the permanent structuring threshold. The role of the cw UV illumination is discussed in terms of inhibition of the silver cluster precursors or of dissolution of the laser-induced silver clusters. These results show the ability of laser writing inhibition in our photosensitive silver-containing phosphate glass, which is a necessary step to further develop super-resolution laser writing approaches such as STED-like DLW either of fluorescent silver clusters or of silver metallic nanoparticles with plasmonic properties. (C) 2015 Optical Society of America

OCIS Codes: (140.339)Laser materials processing, (260.6042) Singular optics, 100.6640 Superresolution, 050.6624 Subwavelength structures, 050.6875 Three-dimensional fabrication.

(190.4180) Multiphoton processes,

During the two last decades, huge progress has been achieved in femtosecond ( $\left.f_{s}\right)$ direct laser writing (DLW), making it both versatile and cost-limited, and pushing it from three-dimension (3D) [1] up to $5 \mathrm{D}[2,3]$. Still, a modern key issue remains the production of structures with sizes much smaller than the diffraction limit, by developing laser-based super resolution approaches, in order to compete with nanoscale manufacturing technologies such as electron or ion beam lithography [4]. Despite great achievements in polymers with stimulated emission depletion based writing processes (STED-like DLW) $[5,6]$, it is still challenging to transpose such a technique to oxide materials for photonic applications, such as the fabrication of metamaterials or artificial atoms [7,8,9]. Future breakthroughs in the production of nanoscale objects should combine efforts in both new laser structuring schemes and innovative glass materials [10].

In this letter, we propose a two-color DLW scheme in a silver-doped phosphate glass, where a cw UV laser beam is used with (co-illumination) or after (post-illumination) the fs writing beam. We report on a remarkable ability to control and even to fully inhibit the fs-DLW efficiency for the creation of fluorescent silver clusters. The involved mechanisms are addressed, opening the way to highly-localized laser-induced structuring.

We developed a silver-containing zinc phosphate glass with a $5 \% \quad \mathrm{Ag}_{2} \mathrm{O}$ concentration (mol. \%), obtained by standard glass melting method, cut and polished to optical quality [11]. When exposed to focused fs laser irradiation, the chemistry of the glass is locally modified, giving rise to fluorescent silver clusters [12]. DLW was performed with two distinct setups. The first one used a Ti:Sa regenerative laser amplifier (Coherent, RegA 9000, up to $1 \mathrm{~W}, 250 \mathrm{kHz}, 100 \mathrm{fs}$ at $800 \mathrm{~nm}$ ). DLW was carried out by tightly focusing the laser pulses (Mitutoyo objective, M Plan Apo VIS, 100× NA 0.9). The pulse duration (FHWM) at the focus in the sample was typically estimated to $145 \mathrm{fs}$, due to the group delay dispersion of the setup. The cw UV coand post-illuminations were performed to achieve DLW inhibition, with a co-propagating focused laser diode (TOPTICA, iBeam smart 395-S, $120 \mathrm{~mW}, 394$ $\mathrm{nm})$. The second setup was based on a Ytterbium fs oscillator (Amplitude Systèmes, T-pulse 200, $9 \mathrm{MHz}$, $390 \mathrm{fs}$ at $1030 \mathrm{~nm}$ ), focused with a microscope objective (Mitutoyo, M Plan Apo NIR, 50× NA 0.55). Here, post-illumination was achieved with a copropagating focused $405 \mathrm{~nm}$ laser diode (OBIS, Coherent, $100 \mathrm{~mW}$ ). For both setups, the number of pulses and transmitted irradiance were controlled by an acousto-optic modulator, preventing any notable self-focusing during DLW (the nonlinear index of our glass being similar to that of fused silica), and leading to weak index changes due to photochemical reactions that correspond to a type-I interaction regime [13]. Sample positioning and translation were performed with a high-precision $3 \mathrm{D}$ stage (XMS-50 and and VP-25XL stages, Micro-Contrôle).

In our silver-containing glass, single-beam DLW results from multiple-step phenomena above the irradiance threshold: (i) multi-photon ionization releases mobile free electrons that diffuse from the 
center to the periphery of the fs laser beam. Their trapping leads to the creation of a strong and permanent buried static electric field (up to almost $\left.10^{9} \mathrm{~V} \cdot \mathrm{m}^{-1}\right)$ [14,15]; (ii) multi-pulse cumulated effects lead to thermal activation of the mobility of the silver ions, which allows for their forced diffusion by the buried static electric field previously grown with previous laser pulses; (iii) the creation and the diffusion of mobile $\mathrm{Ag}^{0}$, lead to the creation of silver clusters. Many articles discuss the nature of silver clusters $[16,17]$. Recently, we also studied our laserinduced clusters, by labeling $\mathrm{Ag}_{\alpha}$ some of them being related to two absorption bands (typically at $287 \mathrm{~nm}$ and $325 \mathrm{~nm}$ ), possibly corresponding to $\mathrm{Ag}_{4}{ }^{2+}$ or $\mathrm{Ag}_{8} 8^{2+}$ clusters. While these $\mathrm{Ag}_{\alpha}$ clusters show a clear stability, they are not large enough to further grow metallic Ag nanoparticles during a heat treatment slightly above the glass transition temperature, contrarily to larger clusters labeled $\mathrm{Ag}_{\beta}$ [18].

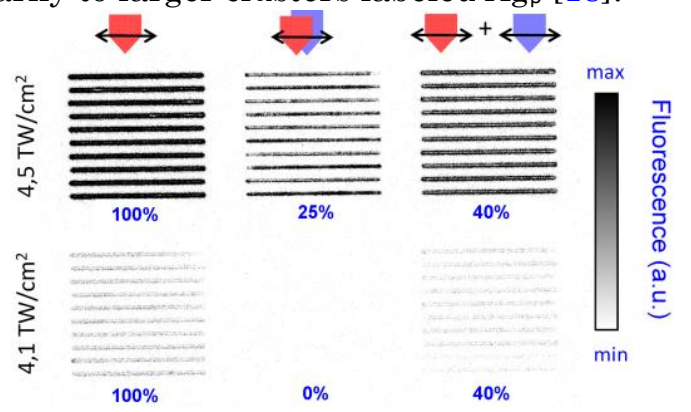

Fig. 1: Influence of dual-color DLW, for two irradiances with single-beam DLW (left), UV co-illumination (center) or UV post-illumination (right) with $\lambda_{\text {inhibition }}=394 \mathrm{~nm}$, observed by confocal imaging $\left(\lambda_{\text {excitation }}=405 \mathrm{~nm}\right)$. Values denote the integrated fluorescence amplitude for each case.

DLW was performed ( $\operatorname{setup~} 1$, speed $=2.5 \mu \mathrm{m} / \mathrm{s}$ ) for two distinct fs irradiances, at $4.5 \mathrm{TW} / \mathrm{cm}^{2}(47.1 \mathrm{~nJ}$ / pulse) and $4.1 \mathrm{TW} / \mathrm{cm}^{2}$ (37.8 $\mathrm{nJ} /$ pulse), by standard single-beam DLW, DLW with UV co-illumination, or DLW with UV post-illumination with a cw UV laser at $394 \mathrm{~nm}$ (Fig. 1). The three different schemes provide significant deviations from one to another. Single-beam DLW with a $4.5 \mathrm{TW} / \mathrm{cm}^{2}$ irradiance creates a given fluorescence response, while for a 4.1 $\mathrm{TW} / \mathrm{cm}^{2}$ irradiation, closer to the threshold of permanent DLW of silver clusters (typically 3.8 $\mathrm{TW} / \mathrm{cm}^{2}$ ), the DLW efficiency is $95 \%$ weaker in absolute value. For the dual-color scheme with a 4.5 $\mathrm{TW} / \mathrm{cm}^{2}$ irradiance, the post- and co-illuminations lead to inhibitions of $60 \%$ and $75 \%$ of the fluorescence response, respectively, with respect to that created with the single-beam scheme. With the weaker irradiation at $4.1 \mathrm{TW} / \mathrm{cm}^{2}$, the dual-color scheme is even more significant since the post- and co-illuminations lead then to $60 \%$ and $100 \%$ inhibitions of the fluorescence response. Indeed, it is more efficient to prevent the silver cluster formation with a UV co-illumination, by inhibiting the development of their precursors, than to erase such clusters with a UV post-illumination once they are created and stabilized inside the glass.

Dual-color DLW was further carried out with the UV co-illumination (setup 1, above $3.8 \mathrm{TW} / \mathrm{cm}^{2}$, $\mathrm{N}_{\text {pulses }}=10^{5}$ ), by varying the irradiances of both the UV $(394 \mathrm{~nm})$ and the IR beams. The related widefield fluorescence imaging (excitation at $405 \mathrm{~nm}$ ) reveals the progressive inhibiting action of the 394 $\mathrm{nm} \mathrm{cw}$ laser (Fig. 2.(a)). Indeed, for DLW at constant IR irradiance, the increase of the $394 \mathrm{~nm}$ power leads to the decrease of the written fluorescence intensity, especially when the irradiance of the fs beam is moderately above the threshold of permanent DLW. For higher IR irradiance, the inhibiting effect of the cw UV beam tends to be less efficient to balance the increasing ability to create silver clusters.

The relative fluorescence efficiency of each DLW condition from Fig. 2(a) has been quantitatively estimated (Fig. 2(b)). It highlights the strong efficiency of the simultaneous cw UV co-illumination to inhibit DLW. Indeed, for moderate IR irradiances (between 4 and $4.2 \mathrm{TW} / \mathrm{cm}^{2}$, corresponding to 36.9 , 38.8 and $40.7 \mathrm{~nJ} /$ pulse), the $394 \mathrm{~nm}$ co-illumination allows for reaching up to $100 \%$ inhibition of the silver cluster creation.


Fig. 2: (a) Interaction matrix of dual-color direct laser writing, with a fs writing beam ( $800 \mathrm{~nm}, 145 \mathrm{fs}, 10^{5}$ pulses) and a simultaneously shined UV laser diode $\left(\lambda_{\text {inhibition }}=394 \mathrm{~nm}, \mathrm{cw}\right)$, being observed in broad-field fluorescence imaging ( $\lambda_{\text {excitation }}=405 \mathrm{~nm}$ and $\Delta \lambda_{\text {collection }}=450-750 \mathrm{~nm}$ ). (b) Integrated fluorescence intensity of each point, enabling an inhibition effect up to $100 \%$.

The inhibiting role of the UV beam was probed by measuring the transmission of the fs beam during DLW without or with UV co-illumination (394 nm laser OFF or ON, full power), as shown in Fig. 3. The transmission of the fs beam always appears larger when the UV beam is ON, even for IR irradiances below the threshold of permanent laser structuring, 
which suggest the UV-induced cancelling of transient modifications. The UV co-illumination influence is more pronounced for IR irradiances above the threshold of permanent creation of silver clusters. Indeed, the creation of $\mathrm{Ag}_{\alpha}$ clusters leads to additional absorption pathways for the writing IR beam [18]. Therefore, the UV co-illumination tends to annihilate the precursors of large silver species, which inhibits the creation of $\mathrm{Ag}_{\alpha}$ clusters and their absorption bands during DLW. Such a transmission analysis shows that energy deposition processes largely evolve during DLW, since the material undergoes pulse-to-pulse modifications, which opens pathways to multi-photon absorption from band-gap excitation due to new chemical species [19].

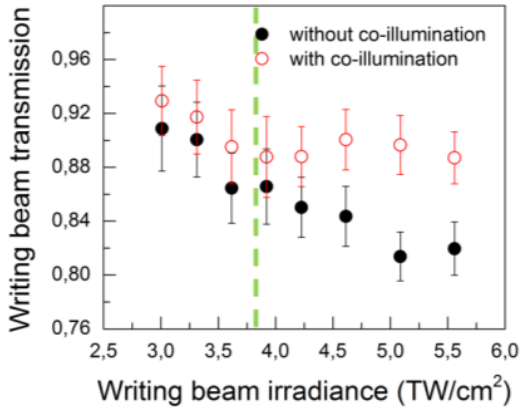

Fig. 3: Transmission of the $f s$ beam during the glass structuring, with and without the presence of the co-illuminating $\mathrm{cW}$ UV beam, showing an increase of the fs beam transmission above the threshold of permanent laser writing (about $3.8 \mathrm{TW} / \mathrm{cm}^{2}$ ) while the UV beam is ON.

The role of the laser-induced modifications during DLW has been studied slightly above the DLW

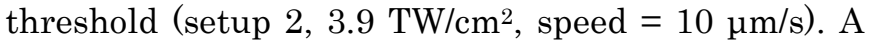
large area has been structured ( $\mathrm{N}$ lines of $2 \mathrm{~mm}$ length, spaced by $4 \mu \mathrm{m})$, and then post-illuminated with a slightly off-focused $405 \mathrm{~nm}$ laser $\left(540 \mathrm{~kW} / \mathrm{cm}^{2}\right.$ through a $0.1 \mathrm{NA}$ objective, speed $\sim 100 \mu \mathrm{m} / \mathrm{s})$ to rescan the whole area and to partially inhibit the laser-induced fluorescence behavior. Fluorescence excitation spectroscopy of such a $1 \mathrm{~mm}^{2}$ structured square has then been measured (Jobin Yvon double monochromator SPEX, gratings with 1200 grooves $/ \mathrm{mm}, 1 \mathrm{~nm}$ resolution) for an emission wavelength at $630 \mathrm{~nm}$ (Fig. 4). Without UV postillumination, the short wavelength peak results from two contributions: $32 \%$ from the $\mathrm{Ag}^{+}$ions of the pristine matrix at $263 \mathrm{~nm}$, and $66 \%$ from the $\mathrm{Ag}_{\alpha}$ clusters at $275 \mathrm{~nm}$. With UV post-illumination, this peak (typically 5 times weaker) shortens due to the relative evolution of its two components: $62 \%$ from the $\mathrm{Ag}^{+}$ions of the pristine matrix at $263 \mathrm{~nm}$, and $30 \%$ from the $\mathrm{Ag}_{a}$ clusters at $275 \mathrm{~nm}$. Moreover, without UV post-illumination, two additional bands are visible, the first one at $330 \mathrm{~nm}$ resulting from the $\mathrm{Ag}_{\alpha}$ clusters, and the second one at $425 \mathrm{~nm}$ (not being attributed). These two bands almost completely vanish under UV post-illumination, which explains the post-DLW erasing of the fluorescence behavior.

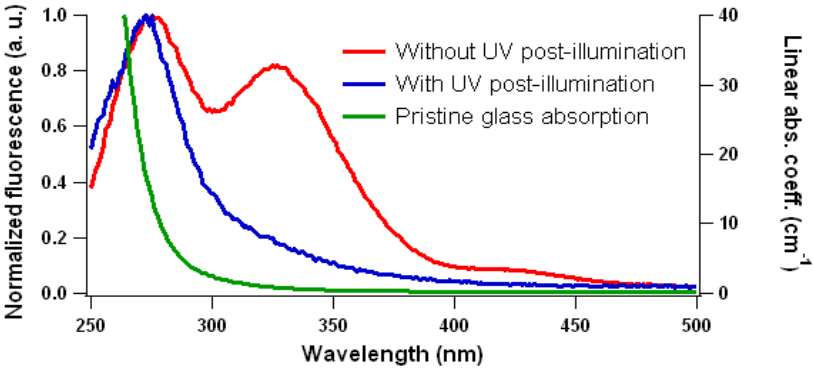

Fig. 4: Normalized excitation spectra (emission wavelength at $630 \mathrm{~nm}$ ) of the fs laser-induced silver clusters without (red plot) or with (blue plot) a cw UV post-illumination, showing that the fluorescence inhibition results from the cancellation of two fluorescence excitation bands of the $\mathrm{Ag}_{\alpha}$ clusters [18] (here at $275 \mathrm{~nm}$ and $330 \mathrm{~nm}$ ) and of an additional band at $425 \mathrm{~nm}$, which globally prevents fluorescence imaging with an excitation at $405 \mathrm{~nm}$. Linear absorption coefficient of the pristine sample (green plot) showing the UV cutoff due to the $\mathrm{Ag}^{+}$ion absorption (which correlates with the fluorescence excitation band at $263 \mathrm{~nm}$.

The ability to achieve fluorescence DLW and its UV-induced inhibition opens promising applications in terms of UV-mastered spatially localized DLW, especially by considering UV rescanning with line-toline spacing much smaller than the diffraction limit, or by using a donut-shaped UV beam, as in the STED approach. The targeted application is to further address super-resolution DLW. A first step towards such a demonstration has been achieved with UV post-illumination, where a set of parallel fluorescent lines have then been perpendicularly exposed to the focused cw $394 \mathrm{~nm}$ beam $\left(4.2 \times 10^{5}\right.$ $\mathrm{W} / \mathrm{cm}^{2}$, speed $\left.=10 \mu \mathrm{m} / \mathrm{s}\right)$, as seen the confocal image of Fig. 5(a) (Leica, SP5, Obj. 63x N.A. 1.3, excitation at $405 \mathrm{~nm}$, integrated spectral range from 450 to 750 $\mathrm{nm}$ ). The UV-induced modulation (Fig. 5(b)) is up to $50 \%$. The observed fluorescence dips of $480 \mathrm{~nm}$ (FWHM) possibly correspond to an overestimation of the size of the focused UV beam, since UV-induced diffusion processes and potential partial overlapping of successive UV passes were not quantified. Still, these fluorescence modulations should be improved with a high NA objective optimized for the UV range.
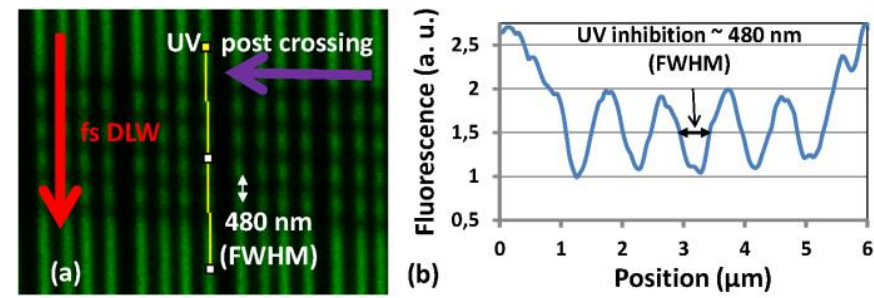

Fig. 5: (a) Confocal imaging of fluorescent lines $\left(\lambda_{\text {excitation }}=405 \mathrm{~nm}\right.$ ) after DLW, and subsequent partial erasing by cW UV post-illumination in the perpendicular direction. (b) 1D profile along the yellow line of Fig. 5(a), showing a fluorescent line with $\mathrm{cw}$ UV induced modulation of a factor 2, with a period of $1 \mu \mathrm{m}$, leading to a $2 \mathrm{D}$ density of spots of $0.15 \mathrm{Gbits} / \mathrm{cm}^{2}$.

The description of the inhibiting role of the cw UV beam is still under consideration, but distinct interpretations can be proposed. In the case of UV coillumination, the trapping of the photoelectrons may 
be partially inhibited, preventing the formation of a buried electric field and thus limiting the creation of favorable reduction-oxidation conditions to grow and stabilize silver clusters. Another interpretation suggests that the inhibition of the silver clustering during the DLW process may occur, despite the maintained existence of the buried electric field. In that case, the UV beam is expected to bring sufficient energy to prevent the formation of intermediate species (very low nuclearity clusters as $\mathrm{Ag}_{2}{ }^{+}$or color centers) occurring during the early stages of the $\mathrm{Ag}_{\alpha}$ cluster creation. This can be related to the better transmission of the fs beam reported in Fig. 3 in the case of the UV co-illumination. In the case of UV post-illumination, such additional optical action may either contribute to limit the buried static electric field (thus restricting favorable reduction-oxidation conditions and thus to partially reduce silver cluster formation) or to directly photo-dissociate some silver clusters through oxidation processes related to electron-hole recombination. As seen in Fig. 1, the effect is more efficient for moderate fs laser irradiances, evidencing that the laser-induced amount of electrons and holes has an impact on the formation of silver clusters. Larger irradiances result in processes that lead to stronger reductive conditions, and to the formation of different types of silver clusters with larger sizes and thus with a more stable behavior with respect to oxidation, as already reported in [18]. Whatever the involved processes, it is less easy to destroy already formed silver clusters with UV post-illumination than to prevent their formation with UV co-illumination (Fig. 2), as intermediate species (very low nuclearity clusters or color centers) are more fragile to UV illumination than clusters with larger sizes. Further studies should focus on the buried electric field under dualcolor DLW, which is beyond the scope of this letter.

In conclusion, we have shown the tunable control of the fluorescent silver cluster creation with a dualcolor DLW scheme, with up to $100 \%$ inhibition thanks to UV co-illumination. These results open the route for STED-like DLW in our silver-containing phosphate glass, in our case with a near-IR multiphoton writing beam and a single-photon UV inhibiting beam, quite similarly to what was performed in polymers. This will further require spatially-structured cw UV illumination (typically bearing a charge-2 vortex) to reduce the active volume of DLW below the diffraction limit as needed to create artificial matter with nanoscale dimensions. Finally, these findings suggest the ability to achieve new sub-diffraction structures by combining both fs IR and cw UV structured light fields, for the spatially-selective inhibition of optical vortex induced laser patterning of linear and nonlinear optical properties [20].

\section{Ackowledgements}

This work was funded by the French Agency of National Research [FELINS 2010 ANR BLAN 946 03], the French Aquitaine Region [FELINS REGION], the Cluster of Excellence LAPHIA [STEDn'STRUCT project]. Confocal imaging was performed at the Photonic Imaging platform of Bordeaux Imaging Center (UMS 420 CNRS).

\section{References.}

1. R. R. Gattass, and E. Mazur, Nat. Photonics 2, 219-225 (2008).

2. P. Zijlstra, J. W. M. Chon and M. Gu, Nature 459, 410413 (2009).

3. J. Zhang, M. Gecevičius, M. Beresna, and P. G. Kazansky, Phys. Rev. Lett. 112, 033901 (2014).

4. F. Watt, A. A. Bettiol, J. A. Van Kan, E. J. Teo and M. B. H. Breese, Int. J. of Nanoscience, 4(3), 269-286 (2005).

5. S. W. Hell and J. Wichmann, Opt. Lett. 19, 780-782 (1994).

6. J. Fischer and M. Wegener, Opt. Mat. Expr. 1, 614-624 (2011).

7. C. Soukoulis and M. Wegener, Nat. Photonics 5, 523530 (2011).

8. G. Dolling, C. Enkrich, and M. Wegener, J. F. Zhou and C. M. Soukoulis, S. Linden, Opt. Lett. 30(23), 31983200 (2005).

9. C. Rockstuhl, C. Menzel, S. Mühlig, J. Petschulat, C. Helgert, C. Etrich, A. Chipouline, T. Pertsch, and F. Lederer, Phys. Rev. B 83, 245119 (2011).

10. A. Royon, Y. Petit, G. Papon, M. Richardson, and L. Canioni, Opt. Mat. Express 1, 866-882 (2011).

11. K. Bourhis, A. Royon, M. Bellec, J. Choi, A. Fargues, M. Treguer, J.-J. Videau, D. Talaga, M. Richardson, T. Cardinal and L. Canioni, J. of Non-Cryst. Solids 356, 2658-2665 (2010).

12. M. Bellec, A. Royon, K. Bourhis, J. Choi, B. Bousquet, M. Treguer, T. Cardinal, J. Videau, M. Richardson and L. Canioni, J. Phys. Chem. C 114, 15584-15588 (2010).

13. B. Poumellec, M. Lancry, A. Chahid-Erraji, and P. G. Kazansky, Opt. Mat. Expr., 1, 766 (2011).

14. G. Papon, N. Marquestaut, Y. Petit, A. Royon, M. Dussauze, V. Rodriguez, T. Cardinal, L. Canioni, J. Appl. Phys. 115, 113103 (2014).

15. G. Papon, Y. Petit, N. Marquestaut, A. Royon, M. Dussauze, V. Rodriguez, T. Cardinal, and L. Canioni, Opt. Mat. Expr. 3, 1855-1861 (2013).

16. B. G. Ershov, G. V. Ionova, A. A. Kiseleva, Rus. J. Phys. Chem. 69, 239 (1995).

17. R. Espiau de Lamaestre, H. Béa , H. Bernas , J. Belloni, J. L. Marignier, Phys. Rev. B 76, 205431 (2007).

18. N. Marquestaut, Y. Petit, A. Royon, T. Cardinal, and L. Canioni, Adv. Funct. Mat. 24, 5824-5832 (2014).

19. E. G. Gamaly, S. Juodkazis, V. Mizeikis, H. Misawa, A. V. Rode, and W. Krolikowski, Phys. Rev. B 81, 054113 (2010).

20. K. Mishchik, Y. Petit, E. Brasselet, A. Royon, T. Cardinal, and L. Canioni, Opt. Lett. 40(2), 201-204 (2015). 


\section{References.}

1. R. R. Gattass, and E. Mazur, "Femtosecond laser micromachining in transparent materials," Nat. Photonics, 2, 219-225 (2008).

2. P. Zijlstra, J. W. M. Chon and M. Gu, "Five-dimensional optical recording mediated by surface plasmons in gold nanorods,"Nature 459, 410-413 (2009).

3. J. Zhang, M. Gecevičius, M. Beresna, and P. G. Kazansky, "Seemingly unlimited lifetime data storage in nanostructured glass," Phys. Rev. Lett. 112, 033901 (2014).

4. F. Watt, A. A. Bettiol, J. A. Van Kan, E. J. Teo and M. B. H. Breese, "Ion beam lithography and nanofabrication: a review," Int. J. of Nanoscience, 4(3), 269-286 (2005).

5. S. W. Hell and J. Wichmann, "Breaking the diffraction resolution limit by stimulated emission: stimulatedemission-depletion fluorescence microscopy," Opt. Lett. 19, 780-782 (1994).

6. J. Fischer and M. Wegener, "Three-dimensional direct laser writing inspired by stimulated-emission-depletion microscopy," Opt. Mat. Expr. 1, 614-624 (2011).

7. C. Soukoulis and M. Wegener, "Past achievements and future challenges in the development of threedimensional photonic metamaterials," Nat. Photonics 5, 523-530 (2011).

8. G. Dolling, C. Enkrich, and M. Wegener, J. F. Zhou and C. M. Soukoulis, S. Linden, "Cut-wire pairs and plate pairs as magnetic atoms for optical metamaterials," Opt. Lett. 30(23), 3198-3200 (2005).

9. C. Rockstuhl, C. Menzel, S. Mühlig, J. Petschulat, C. Helgert, C. Etrich, A. Chipouline, T. Pertsch, and F. Lederer, "Scattering properties of meta-atoms," Phys. Rev. B 83, 245119 (2011).

10. A. Royon, Y. Petit, G. Papon, M. Richardson, and L. Canioni, "Femtosecond Laser Induced Photochemistry in Tailored Materials," Opt. Mat. Express 1, 866-882 (2011).

11. K. Bourhis, A. Royon, M. Bellec, J. Choi, A. Fargues, M. Treguer, J.-J. Videau, D. Talaga, M. Richardson, T. Cardinal and L. Canioni, "Femtosecond laser structuring and optical properties of a silver-containing glass," J. of Non-Cryst. Solids 356, 2658-2665 (2010).

12. M. Bellec, A. Royon, K. Bourhis, J. Choi, B. Bousquet, M. Treguer, T. Cardinal, J. Videau, M. Richardson and L. Canioni, "Beat the diffraction limit in $3 D$ direct laser writing in photosensitive glass," J. Phys. Chem. C 114, 15584-15588 (2010).

13. B. Poumellec, M. Lancry, A. Chahid-Erraji, and P. G. Kazansky, "Modification thresholds in femtosecond laser processing of pure silica: review of dependencies on laser parameters [Invited]," Opt. Mat. Expr., 1, 766 (2011).

14. G. Papon, N. Marquestaut, Y. Petit, A. Royon, M. Dussauze, V. Rodriguez, T. Cardinal, L. Canioni, "Femtosecond direct laser poling of sub-micron, stable and efficient second-order optical properties in a tailored silver phosphate glass,” J. Appl. Phys. 115, 113103 (2014).

15. G. Papon, Y. Petit, N. Marquestaut, A. Royon, M. Dussauze, V. Rodriguez, T. Cardinal, and L. Canioni, "Fluorescence and second-harmonic generation correlative microscopy to probe space charge separation and silver cluster stabilization during direct laser writing in a tailored silver-containing glass," Opt. Mat. Expr. 3, 1855-1861 (2013).

16. B. G. Ershov, G. V. Ionova , A. A. Kiseleva, "Silver clusters: calculations of optical transmissions and of the formation and properties of "magic" positively charged clusters," Rus. J. Phys. Chem. 69, 239 (1995).

17. R. Espiau de Lamaestre, H. Béa , H. Bernas , J. Belloni, J. L. Marignier, "Irradiation-induced $A g$ nanocluster nucleation in silicate glasses: Analogy with photography," Phys. Rev. B 76, 205431 (2007).

18. N. Marquestaut, Y. Petit, A. Royon, T. Cardinal, and L. Canioni, " $3 D$ silver nanoparticles formation using femtosecond laser irradiation in phosphate glasses: analogy with photography," Adv. Funct. Mat. 24, 58245832 (2014).

19. E. G. Gamaly, S. Juodkazis, V. Mizeikis, H. Misawa, A. V. Rode, and W. Krolikowski, "Modification of refractive index by a single femtosecond pulse confined inside a bulk of a photorefractive crystal," Phys. Rev. B 81, 054113 (2010).

20. K. Mishchik, Y. Petit, E. Brasselet, A. Royon, T. Cardinal, and L. Canioni, "Patterning linear and nonlinear optical properties of photosensitive glasses by femtosecond structured light," Opt. Lett. 40(2), 201-204 (2015). 